Service Charge Management at the Dawning of the Age of the Professional Statement

\begin{tabular}{|r|l|}
\hline Journal: & Property Management \\
\hline Manuscript ID & PM-02-2020-0011.R1 \\
\hline Manuscript Type: & Research Paper \\
\hline Keywords: & $\begin{array}{l}\text { Benchmarking, Service charges, Best practice, Financial Reporting, Code } \\
\text { of Practice }\end{array}$ \\
\hline
\end{tabular}

SCHOLARONE ${ }^{m}$

Manuscripts 


\title{
Service Charge Management at the Dawning of the Age of the Professional Statement
}

\begin{abstract}
Purpose - The paper provides a snapshot analysis on the state of service charge management at the point in which its regulatory framework by RICS changed from a voluntary code of practice to a mandatory professional statement.
\end{abstract}

Design/methodology/approach - The data consist of a unique eight-year longitudinal study of service charge statements and practice (2010-2017). Because of the confidential nature of such business-sensitive information, these are a priceless study of real world practice over such a long period and are able to illustrate both annual compliance, but also the year-on-year changes. Given this, it is recognised that data are skewed in favour of compliance because they are derived from an actively managed portfolio.

Findings -The results continue to illustrate long-running problems of non-compliance with 'required' metrics. Given the inherent bias in the data, this is especially difficult to excuse. The paper also analyses the results in the light of the new RICS professional statement, which requires mandatory compliance. Whilst some of the metrics are advisory, there remain questions over how the RICS might realistically enforce so many practitioners to change their existing performance and how willing the Institution might be to actually prosecute failure. It also revisits the issue of institutionalised benchmarking of standards. Intriguingly, there are islands of almost perfect compliance, which offers an interesting contrast and raises further research questions on why some practitioners provide such exemplary work.

Research limitations/implications - The data are derived from the clients of a UK property management consultancy. This does preclude any randomness to the sampling. However, the richness of the data and the methodology adopted provide valid data.

Originality/value - This work offers both unique data and an eight year longitudinal analysis, but also a timely comparison with the requirements within a new RICS Professional Statement. This shift in regulatory regime reinforces the value of the work.

Keywords - Benchmarking, Service charges, Best practice, RICS Code of Practice, Financial Reporting

Paper type - Research paper

\section{Introduction}

The paper considers the efficiency of service charge management within the UK office sector at a crucial time for the field; the introduction of a mandatory RICS professional statement. The adoption of such a device has long been deemed 
unnecessary by the profession (see, for example, RICS 2009, RICS 2010) and so the shift in attitude is something of a volte face.

The paper focuses upon ten metrics to analyse whether real world practice conforms to the expectations laid out by the RICS in their new Professional Statement, built upon previous codes of practice. The metrics are selected because they have become a standard benchmark for judging performance within the sector (Eccles and Holt 2009). By utilising accounting characteristics of the service charge process, it allows the researcher to postivistically benchmark compliance in a rigorous and non-subjective process whilst utilising only straightforward descriptive statistical analysis.

\section{The Service Charge}

The purpose of the service charge is to cover payments for the maintenance and upkeep of those common areas in multi-let buildings that are not the responsibility or in use by only one tenant. Where a single tenant occupies the entire space, then there is no need for a service charge. A service charge is only payable if the lease specially requires it, and each individual lease agreement may or may not contain specific provisions concerning what charges might be levied, and how. The service charge can be viewed as a typology of opposing interests, but its process is usually seen as biased in favour of landlords because of its opaque nature (Stapleton 1985). The landlord seeks to recover all expenditure from the tenant (Edward and Krendel 2007); the tenant sees these as the responsibility of someone else and will look to minimise payment only to those items expressly recoverable in the lease (Noor and Pitt 2009).

\section{Service Charge in Practice}

Given that ever since the first 'modern' analysis and practice manual (Stapleton 1985), the service charge has been seen as biased, expensive and lacking transparency it is no surprise that there are a number of themes within the literature. This paper continues an examination of efficiency in managerial practices begun by Calvert (2008), who also benchmarked charges - and noted widespread variety in both.

However, from a building management perspective, two further themes are surfacing. Firstly, since service charges are levied to pay for maintenance and upkeep only, there is increasing discussion on what might be defined as 'maintenance' and 'upkeep' (recoverable), and what might be 'improvement' (unchargeable). As buildings become more complex and expectations change, issues concerning what 'maintaining' might include have become more contentious (see, for example, Noor and Pitt 2009). Given the growing demands on 'old' buildings to do 'new' things, the issues surrounding retrofitting are only going to increase the pressures on how to interpret this issue. 
The second area of interest is in the role of the lease. Given its importance in setting out what can and cannot be done by the landlord, one might assume that these would be drawn up to clearly define what can and should be levied for. One might also expect that precedent from property matters within the courts system would drive clause writers to coalesce around proven solutions and standardise against judgements. However, where the clarity and content have been the subject of investigation (see, for example, Halvitigata 2018, Holt and Eccles 2019) and, despite the existence of best practice 'standard forms', the quality and clarity of leases still being drawn up has been described as "a legal barrier in the development of best practice" (Holt and Eccles 2019: 285).

\section{Service Charge as a Narrative}

For the purposes here, the literature concerning service charges falls within two, associated, narratives.

The first concerns service standards and whether tenants (occupiers) receive fair value. Calvert (2008) established a series of benchmark costs for comparison and longitudinal analysis. Others referred to tenant satisfaction surveys (see, for example, Property Industry Alliance 2012). There is disagreement on exactly how poor service standards are, but most independent observers agree that the overall service level is not acceptable. It is unclear why tenants allow this situation persist; the relative low level of charges compared to rent and profitability is usually seen as a factor. Certainly, in the Credit Crunch, a shift in this attitude was seen as profits fell and all costs were carefully examined.

This line of argument leads to a discussion of how standards can be improved, led by a discussion on why performance was poor. Holt, Eccles and Bennett (2011) argue that performance is very poor because of low fees and small profit margins. This renders the field both unprofitable and generates only disinterest in resolving mediocre quality practice. Their evidence is subjective through the interviewees in their work, but has been accepted as the most plausible explanation. Their paper calls for the need to standardise professional practice, to the extent that it presents proposed certificates, statements and schedules that should be used by practitioners. By enforcing a minimum standard, and by controlling the process by which work is carried out, quality will be upgraded and can then be enforced. This directly engages with the second thread of the literature, which is the various codes and their evolution, and whether a regulatory regime of compliance monitoring to stated performance standards and protocols is required.

There is a long and contested narrative over the quality of performance within service charge management and the desirability of professional (and statutory) regulation of the occupation. The field was only subjected to the most generalised regulatory practice and that late in the last century (Unknown 1996, Guide to Good Practice Working Party 2000). Before then, Stapleton (1985) provides the first practice handbook, and it is quite clear: service charge procedures heavily favour landlords. Some surveying companies offered their own codes (see, for example, 
Drivers Jonas $1990,1995,2000$ ) on the basis that fairer tenancies would generate happier tenants, prepared to pay higher rents and take up more space. None of these offered any prescription and provided only generalised and conceptual intent. They certainly could not be described as practice manuals. The first semi-formal institutional regulatory framework was not established until 2006 (RICS 2006).

Most literature in the last decade points to only poor performance, with limited (if any) improvement, against those benchmarks required by an evolution of various codes of practice (RICS 2006, RICS 2011, RICS 2014) (see, for example, Calvert 2008, Eccles and Holt 2009, Eccles, Holt and Zatolokina 2011 and Holt 2015). This core dispute on the extent to which service charge management might be described as inadequate, has seen RICS resisting formalising a mandated best practice system. It established a transparency working group (RICS 2009, RICS 2010) that broadly refuted criticism of existing practice standards. The codes of practice adopted not only a voluntary approach, but also preferred a 'light touch' regime in which definitive rules were not seen as necessary in engendering a good management service. Compliance metrics that might measure and regulate professional competence were left in the hands of private companies offering consultancy services (see, for example, Jones Lang LaSalle 2012, RealService 2013).

RICS has always argued that, albeit anecdotal, evidence from their membership has never registered any problem with professional practice (RICS 2009), and that without any proof to the contrary, it was reluctant to disadvantage its members against non-members also working within the field by forcing them into (expensive) regulation. RICS transparency working group (RICS 2010) proposed a consultationbased evolutionary program of improvement through greater penetration into the membership of a voluntary code, whilst accepting that this contrasted with its recommendations in most other fields of increased self-regulation and even encouraging statutory legislation.

Obviously, the Professional Statement can be seen as bringing this 10 year conception to an end. Its current Professional Statement (RICS 2018), effective from 1 April 2019, brought to an end this series of voluntary codes of practice (RICS 2006, RICS 2011, RICS 2014).

\section{Methodology}

The research uses data that have been generated from 100 properties under the active management of a service charge consultant. The data are, therefore, not randomly generated but have been selected as a framed sample for the period 20102017. Selection criteria are based on the practical requirement that the properties were managed over the period in question and agreed to allow their confidential financial data to be utilised.

From these data, straightforward descriptive statistical metrics are calculated. Ten metrics have been selected for longitudinal analysis. These are related to accounting processes and reflect procedures for presenting costs, collection protocols and 
administrative processes in managing the service charge process. In addition to their importance, some might be regarded as really quite basic office practices, which makes them undemanding as a measure of service provision. It continues a tradition (for example, Calvert 2008, Eccles and Holt 2009) of measuring the financial management metrics surrounding the service charge as a suitable proxy for the professional standards found in service charges.

From a methodological perspective, each characteristic is relatively certain and provides a reasonably secure guarantee of accuracy. All can be checked by archival research because they relate to documentary processes. Again, the framed sampling used ensured that all data existed in a concrete form and could be physically proven. And the nature of the metrics relates to facts - for example, whether an account was sent within 4 months or not.

Over the course of the time period, there may have been some shifts within the various iterations of best practice guidance, but these will be noted further on where it might be seen as materially important. Thus whilst the statistical analysis is simple, it reflects the binary nature of the data: a practice was followed, or it was not. For example, a deadline was achieved, or it was not.

The nature of the buildings under study are unimportant to the principle being investigated. It would be possible to drill down and divide the sample by owner, tenant, building size, location or any other variable. However, this is superfluous to the aim of this particular paper. The properties are offices, large enough to have multiple occupiers that can afford to employ a service charge agent to represent them. There is nothing of interest to this paper as to whether financial service companies receive a better service than retailers, or Bristol buildings are better managed than Blackburn ones.

What this means for data reliability, of course, is that they are biased because they are actively managed service charge activities, and are expected to perform better than unmanaged ones. Where an actively managed portfolio can only achieve the results discussed below, one can only speculate on bad might be the results for occupiers simply accepting a default service. Even so, the ability for the research to follow the same service charge management process for each building over the eight year period is an invaluable and unique data set and the sole purpose of the data in this paper.

Establishing the precise value of the metrics to be measured is relatively straightforward in practice. Firstly, we have the lease, which may, or may not, describe the financial reporting, management, administrative, and audit processes that apply when managing the service charge process. Where an individual lease is silent in terms of these requirements, the main practical guidance for the facilities manager or managing agent comes from the mandatory RICS Professional Statement, Service Charges in Commercial Property (RICS 2018), which replaced the non-mandatory RICS Code of Practice, Service Charges in Commercial Property (RICS, 2014). There are, therefore, usually quite specific standards that practice can be assessed against. 
The data set here, 2010-2017, offers a useful judgement on the transparency group's strategy, but also provides a current state of play at the dawning of this new age.

The work is divided into two sections: firstly, an analysis on the historic quality of service on the 100 buildings is presented, and this is then followed by a discussion of how the new professional statement establishes standards for the future. The first provides a contextual basis to allow us to judge prevailing standards, that will then allow us to make a judgement on the merits of the practice standards adopted.

\section{Benchmarking RICS Code Metrics}

The metrics selected for the paper are those that have been utilised in previous works, as discussed above. This allows the paper to add to existing knowledge on performance whilst using an established and credible testing regime.

The precise metrics are as follows:

Timely delivery

Fixed management fee

Cost classes used

Variances explained

Interest credited

Apportionment explained

Signed off by manager

Accounting principles disclosed

Schedule of accruals provided

Each metric is discrete and data are readily self-explanatory. Therefore, only simple descriptive statistical analysis is employed in this paper. Because this paper only examines practice on each issue, it does not look for correlation and nor does it offer a view on the reasons for the performance. These are beyond the scope of this particular work. However, those managers that were non-compliant tended to show consistency in non-compliance, and no metric offered any clear indication of its role as a determinant or driver of other behaviours.

As discussed earlier, since the data is also aggregated for all 100 buildings, a second development might be to track individual buildings to examine whether there was any shift in the performance on a 'by building' analysis. A preliminary analysis suggests that some buildings improved and others worsened when data were amalgamated, but as there is no corresponding analysis then these data were not presented here. 
Obviously, these data pre-date the new statement. The paper will first establish how well these metrics were followed, and then offer a viewpoint on how the new rules compare with those having been measured. Together, they provide a commentary on the state of service charge management as it enters the new regulatory regime.

\section{Historic Service Provision Benchmarked}

This section measures the performance standards achieved by the building owners and their agents against the metrics discussed earlier.

Table 1 provides a summary of the statistics within these metrics for each year between 2010 and 2017, and a discussion of each point follows.

\begin{tabular}{|c|c|c|c|c|c|c|c|c|c|c|}
\hline Year & $\begin{array}{r}\text { Timely } \\
\text { delivery }\end{array}$ & $\begin{array}{r}\text { Fixed } \\
\text { management } \\
\text { fee }\end{array}$ & $\begin{array}{r}\text { Cost } \\
\text { classes } \\
\text { used }\end{array}$ & $\begin{array}{r}\text { Cost } \\
\text { categories } \\
\text { used }\end{array}$ & $\begin{array}{l}\text { Variances } \\
\text { explained }\end{array}$ & $\begin{array}{l}\text { Interest } \\
\text { credited }\end{array}$ & $\begin{array}{r}\text { Apportionment } \\
\text { explained }\end{array}$ & $\begin{array}{l}\text { Signed off } \\
\text { by manager }\end{array}$ & \multicolumn{2}{|c|}{$\begin{array}{l}\text { Accounting Schedule of } \\
\text { principles accruals } \\
\text { disclosed provided }\end{array}$} \\
\hline 2017 & $46 \%$ & $41 \%$ & $45 \%$ & $39 \%$ & $58 \%$ & $42 \%$ & $92 \%$ & $81 \%$ & $36 \%$ & $23 \%$ \\
\hline 2016 & $56 \%$ & $37 \%$ & $43 \%$ & $32 \%$ & $50 \%$ & $37 \%$ & $93 \%$ & $81 \%$ & $36 \%$ & $17 \%$ \\
\hline 2015 & $46 \%$ & $80 \%$ & $45 \%$ & $42 \%$ & $54 \%$ & $42 \%$ & $85 \%$ & $81 \%$ & $31 \%$ & $8 \%$ \\
\hline 2014 & $59 \%$ & $82 \%$ & $48 \%$ & $39 \%$ & $52 \%$ & $39 \%$ & $88 \%$ & $83 \%$ & $34 \%$ & $1 \%$ \\
\hline 2013 & $56 \%$ & $70 \%$ & $49 \%$ & $49 \%$ & $54 \%$ & $29 \%$ & $91 \%$ & $73 \%$ & $31 \%$ & $0 \%$ \\
\hline 2012 & $68 \%$ & $61 \%$ & $45 \%$ & $44 \%$ & $39 \%$ & $30 \%$ & $96 \%$ & $66 \%$ & $9 \%$ & $0 \%$ \\
\hline 2011 & $56 \%$ & $53 \%$ & $39 \%$ & $47 \%$ & $41 \%$ & $24 \%$ & $92 \%$ & $56 \%$ & $1 \%$ & $0 \%$ \\
\hline 2010 & $82 \%$ & $21 \%$ & $26 \%$ & $26 \%$ & $24 \%$ & $32 \%$ & $68 \%$ & $31 \%$ & $3 \%$ & $0 \%$ \\
\hline
\end{tabular}

\section{Timely delivery}

It is expected that documentation should be timely, and this has been a stated expectation throughout the period under review. Budgets are required "at least one month prior to the start of the service charge year" (RICS 2006, p.5) whilst "the owner will submit certified accounts to the occupiers in a timely manner and in any event within four months of the end of the service charge year" (ibid, p.13). These stipulations are repeated in the 2011 version, for example: "Detailed statements of actual expenditure, together with accounting policies and explanatory text, will be issued within four months of the service charge year end" (ibid, p.6). Yet less than half achieved this in 2017 and data show a steady decline from a not unreasonable starting point in 2010 of over four fifths.

The fact that this metric not only worsened, but did so quite remarkably is, in itself, quite startling. It also contradicts the RICS' central argument on a gradual improvement through the informal dissemination of best practice ideas. There is no explanation from any documentation (such as a change in managing agent for part 
of the sample) as to why compliance has fallen sharply. However, the result is clear: there is poor compliance, and a declining rate.

This metric also turned up examples of poor office practice as well, where documents failed to include a clear date of issue on the document and/ or accompanying letter from the managing agent. In fact, the 2011 Code, unlike the 2006 version, explicitly required a "date of issue" (RICS, 2011, p.26). The fact that documents do not bear a date, however, reinforces the inference that practice management is simply not acceptable.

\section{Fixed management fee}

Whilst the 2006 version did not prohibit percentage fee charging systems, it did state that there should be "a fixed fee for a reasonable period of time" (RICS, 2006, p.12). It appears to be not unusual practice to charge a proportional fee prior to the code. However, the 2011 Code stated: "fees are set on a fixed price basis rather than being calculated as a percentage of expenditure. Percentage is no longer appropriate and is considered to be a disincentive to the delivery of value for money. The management fee should be a fixed fee subject to annual review or indexation" (RICS, 2011, p.12). Therefore, it has been recognised throughout the period that a fixed fee is preferable and serves the tenant better.

It is tempting to credit this shift in attitude for the improvement in the results between $2010(21 \%)$ and $2011-2012$ (53\% rising to $61 \%)$ and which then progressed to $80 \%$ in 2015. But the collapse of the score in 2016 and 2017 in what is seen as an issue that had no valid objection is very worrying.

Whilst it can thus be argued that, again, compliance is problematic, the entire conception of recharging was revisited in the consultation for the professional statement. It proposed to return to only an advisory on this, contradicting the certainty provided in 2011. However, the final Professional Statement determined that a fixed fee was required - unless overridden by the lease. This illustrates how the profession itself remains unsure of the most appropriate charging system.

\section{Cost classes used}

A three tier coding structure is used by all of the codes when classifying and reporting service charge expenditure:

- Cost classes;

- $\quad$ Cost categories; and

- $\quad$ Cost codes (2006 Code terminology) or descriptions (2011, 2014 Code terminology).

This classification provides a hierarchical division of service charge expenditure, although the Code only requires the use of cost classes and cost categories. 
Classes are broken into categories, which in turn contain more precise descriptions (codes) of the costs incurred. Analysis of documents focused on the use of the first two tiers of cost classification, since the third is optional. The analysis required some subjective judgement on whether this was done consistently, but was carried out using predetermined objective criteria.

Once again, the latest figures show a relapse. Whilst the period 2011-2015 never managed a halfway compliance, it mostly showed a consistent advance from the basepoint in 2010. But not only did 2016 show a fall of ten percentiles, the 2017 figure of $39 \%$ is little better and disappointing. It is clear that there is little appetite by agents for investing into a coding system that they do not regard as useful.

\section{Variances explained}

The 2006 Code required that the budgets and accounts should be issued with a report that provides "explanations of significant individual costs and of variances from the previous year's budget/accounts" (RICS, 2006, p.13). In a similar way, the 2011 Code required that the service charge accounts provide "an analysis of any material variances between budget and actual expenditure with a detailed commentary to explain trends and variances where these are significant" (RICS, 2011, p.22). An explanation of significant variances from planned expenditures is vital since this information allows occupiers to assess whether managing parties are appropriately planning and managing service charge expenditures.

As what should be a core issue - explaining deviation from agreed budgeting - this metric has at least managed a (mostly) consistent above half response. It is also a rare good news story, in that it is at its highest level over the eight years. In this case, the data supports the RICS support for evolutionary change, albeit $41 \%$ failing to do so in 2017 would be seen by many to be appallingly bad.

\section{Interest credited}

Service charge monies be kept in individual bank accounts and interest generated on such accounts should be credited to benefit of the occupiers. The poor performance of this metric, albeit one that showed improvement in 2017 and, on average, over the study period, might be explained by the low interest rates operating over the last decade. But it does seem to contradict wider RICS views on the ethical requirements on members to manage clients' money carefully.

\section{Apportionment explained}

That it is essential for service charge documents to disclose the basis for apportioning service charge costs between occupiers is self-evident. However, the codes require that the budget and yearly accounts should be issued with a report that explains the basis for this apportionment, and that it should be fair and reasonable. 
This metric is obviously a core service charge issue and one with a high compliance. However, even with further improvement in 2016 and 2017, it is troubling that almost one in ten are failing to show how service charges are apportioned. This does point to a core of service charge managers that are quite simply never going to comply without some degree of enforcement.

\section{Signed off by manager}

Whilst best practice might suggest service charge documents are signed off by either a surveyor or an accountant, or indeed both, in order to ensure the quality and accuracy of the service charge process, the 2006 Code did not require this. It is possible this is because it is a requirement written into many leases.

Notwithstanding, the omission was rectified in the 2011 Code, which introduced a formal requirement that annual statements of service charge expenditure should be certified by an appropriately qualified manager as to whether:

- $\quad$ they provided an accurate record of service charge expenditure incurred;

and

- the expenditure being recovered was in accordance with the terms of the lease.

With the introduction of the Code, the sign off compliance rate improved from $31 \%$ (2010) and only two thirds in 2012 to almost four fifths - and stayed there. This shows marked improvement, whilst, unfortunately, also evidencing a plateau of strong reactionary elements against such standardisation of procedure by service charge managers.

\section{Accounting principles disclosed}

The longitudinal metric here needs a little care when analysing because it was only the 2011 Code that made a requirement on this. Whilst it was possible that provision was made within the lease for the adoption of a specific form of accounting practice, this was unlikely (Holt, Eccles and Bennett, 2011). So, only in the 2011 version was there a formal requirement to disclose the accounting principles and policies used during the preparation of the service charge accounts. Of course, the adequate disclosure of accounting principles and policies is essential to both understanding and auditing any financial statement, so not only was this change long overdue, but those failing to do so were at least guilty of poor professional practice.

The improvement from almost nil in 2010 and 2011 is evidence that RICS' policy of gradual improvement had some effect. From 2013 until 2017, almost a third of practitioners complied. Unfortunately, at the same time, not only does this mean that two thirds did not, it also showed another plateauing compliance statistic and one that was clearly not shifting through a voluntary process. 


\section{Schedule of accruals provided}

The requirement that "all statements of service charges should be prepared on an accruals basis" (RICS, 2014, p.50) was only introduced in the 2014 Code, which explains the nil take-up before 2014. However, whilst showing steady growth, compliance remains only around a fifth. On the one hand, it is difficult to understand the refusal to use the method since, from a financial accounting perspective, it is the only rational approach. However, as will be discussed below, the initial refusal to mandate its use shows that the surveying profession struggles to see the validity in this method.

\section{Overview: Gradual Improvement}

As was discussed earlier, RICS' institutional approach was to promote the voluntary Code of Practice and point to a gradual dissemination of best practice and improvement in the metrics. This has some credibility if one accepts the premise that low fee levels discourage service improvement or modernisation. However, whilst some areas of excellent practice have developed, the typical office occupier continues to receive a service well below that proposed. The evidence presented here reinforces the evidence from throughout this period that occupiers do not receive a 'best practice' service and that the service charge management occupation is not of a professional standard. This is a situation that has persisted for over a decade of oversight by RICS.

\section{The New Professional Statement: A Paradigm Shift?}

Having benchmarked a decade of service standard, and discussed its failings, the following section attempts to offer some perspective on the new requirements.

At first view, the regulatory regime has now changed because RICS has elected to upgrade its latest Code of Practice into a Professional Statement, which is, therefore, mandatory practice. However, whilst Professional Statements are mandatory, there are also different levels of enforcement within them. Basically, there are three grades of requirement:

"Sections within professional statements that set specific mandatory requirements for members use the word 'must'. Members must not depart from specific mandatory requirements.

Sections within professional statements that set an expectation or recommend best practice advice use the word 'should'. Where members depart from these, they should do so only for justifiable good reason. Where, in the professional judgment of the member, the departure may have a material impact on the surveyor's advice, the client must be informed in writing of the departure and the reason/s for the departure.

Any content that does not use the word 'must' or 'should' is information" (RICS 2017). 
So, whilst all RICS members must act in accordance with a professional statement, the force behind what they must do is rather more nuanced.

This, therefore, raises the question as to how the Professional Statement actually mandates practice for each of the metrics discussed above. It is also useful to compare the final paper (RICS 2018) with how the consultation (RICS 2017) proposed to deal with the metrics discussed within this paper.

\section{Timely delivery}

It is one of the core mandatory principles that service charge budgets "are issued annually" (RICS 2018: 10). The requirements for one month (budgets) and four months (reconciled accounts) remain, but as 'should' best practice advice only. Both documents refer to "timely and regular communication" (RICS 2017, section 1.2, point 20; RICS 2018: 12), and the professional statement refers more generally to consultation, the effectiveness of communication and the need for transparency. $A$ decision has clearly been taken to offer advisory deadlines, but not restrict these with the provision that tenants can fall back upon assurances of effective communication over box-ticking timelines.

\section{Fixed management fee}

Whilst the proposals retained the requirement that "management fees should be on a fixed-price basis" (RICS 2017, section 1.2, point 1) (author emphasis), the view that percentage fee pricing is inherently flawed was thereby disavowed and its use was permitted. The final Professional Statement discarded this: "The professional statement requires that fees be set on a fixed-price basis" (RICS 2018: 14) (author emphasis). It also considers the issue of other professional fees and admits that some leases might require a proportional fee charge.

\section{Cost classes used}

Industry standard cost classifications fall into the 'should' class of practice, which means that it is recognised that other approaches might be valid. This has consequences for the profession as a whole since it potentially makes any form of industry benchmarking and comparison difficult because there may be no comparability across service charge data. For national occupiers this will also make their own cost analyses more difficult. However, the professional statement does recognise the advantages of benchmarking, although it also cautions their limitations as well. Still, since adoption is only 'recommended', the reality is that RICS are not directly supporting benchmarking and the use of indices.

One interesting aside is that, despite being 'should' rather than 'must', the statement says that "as a minimum acceptable level of reporting" (original emphasis) cost classes and cost category "should" be used and provides an appendix of 
classifications that "should be used" (RICS 2018: 25). The juxtaposition of a 'should' with a highlighted 'minimum' is interesting.

\section{Variances explained}

Whilst both budgets, final accounts and apportionment schedules are mandatory, it is not a core principle to explain variances between budgets and final accounts. There is a deal of discussion on the auditing of accounts and use of independent accountants that might be taken to infer that variances would be discussed somewhere. And the 'transparency' core principle comments that "prompt notification of material variances ... ensures better working relationships (RICS 2018: 12). The consultation proposed that as a minimum a report is produced that provides "a comprehensive level of detail to enable occupiers to compare expenditure against estimated budget" (RICS 2017, section 6.4). However, this places the onus on the occupier to understand the variance rather than the owner (or agent) to explain it. The published professional statement simply points out for the need of variances to be notified "promptly" (if "significant") and for "summary details of tenders and the process used" together with "the process to be adopted for keeping occupiers informed" for "significant" variances and "major" works (RICS 2018: 21).

Of course, mandating timeliness periods in practice is probably impractical, but there is little real credibility here that occupiers can rely or enforce any quality standard on what the professional statement itself recognises is a situation where "occupiers are entrusting their business overheads/ operating costs to an external manager" (RICS 2018: 21).

\section{Interest credited}

It is a mandatory requirement, as will holding client money in a discrete account.

\section{Apportionment explained}

Again, it is mandatory to produce an annual apportionment schedule.

\section{Signed off by manager}

An "approved set of service charge accounts showing a true and accurate record of the actual expenditure constituting the service charge" is mandatory practice (RICS 2018: 10). The use of independent audit is also discussed at length, and the core principles are quite clear on the need for a "manager's certificate" and an independent review in line with ICAEW Technical Release Tech 09/14BL.

\section{Accounting principles disclosed}


As discussed above, there is a requirement that the accounts are a true and accurate record and reference is made to the relevant ICAEW technical note. The best practice supporting advice is for a "comprehensive list of accounting policies and principles" (RICS 2018: 23).

\section{Schedule of accruals provided}

From a normal financial accounting perspective, the issue of the use of accruals accounting is so obvious that it is difficult to rationalise why it has been such a contentious issue within service charge management practices. The 2014 Code appeared to have finally laid this to rest. However, the consultation referred to "whether" (RICS 2017, section 6.1) the statements are on an accruals basis and this pointed to a return to the pre-2014 codes. This seems to reflect another shift in opinion within the Institution as to what constitutes 'best practice'. However, the final professional statement endorses - broadly - the use of the accruals concept. The glossary states it as "considered to be the standard accounting practice for most service charges" (RICS 2018: 3), although the best practice principles still refer to "whether" the accounts are prepared under an accruals basis. The statement seems to suggest that many leases provide for a cash basis (although there is no evidence to support this) and also appears concerned that it might be too onerous for "very small operations" (RICS 2018: 3).

\section{Professional Statement in Summary}

Overall, whilst the Professional Statement itself is a volte face from previous RICS policy, the result is rather more evolutionary. Most of the provisions proposed are only advisory - albeit with the proviso that variance from its requirements will need very clear explanation. It is not an insignificant shift in policy that the $50-80 \%$ of professionals that fall outside the compliancy metrics evidenced here, in the first section of the paper, would be required to inform their clients in writing with a rationale of why they were not performing to those standards. That in itself is a very strong nudge for behavioural change. However, quite what RICS would do if they did not, remains to be seen.

\section{Conclusions}

Office occupiers receive poor service when compared to the metrics that have been established to judge the meaning of 'best' practice, a situation that has persisted through the range of years under study. And, whilst there are some areas of improvement and some service providers that are excellent, there are others that are worsening - and this from a very low base to start with. Further, because these data are derived from an actively managed service charge management process, then the results can be taken to be better than would be achieved without the employment of a consultant to enforce improved service to the occupier. Some of the metrics are also straightforward good office practice, and yet continue to not happen. Even 
something as straightforward as apportionment, informing occupiers how charges have been allocated has consistently failed to happen for years in one in five cases. For a so-called professional occupation this is very disappointing.

RICS has now decided that evolutionary improvement through voluntary guidance is not enough and has implemented a 'professional statement' regime onto practice. However, in most cases, they have elected to state what 'should' happen, rather than what 'must'. This is interesting because the research here, and elsewhere, is not that practitioners are providing better standards of service, or even equivalents, but that they are simply not performing. Given this, it seems unlikely that they will now be able to articulate a persuasive rationale for their decision not to follow the statement and to continue to offer services that fail these metrics. In effect, this makes the professional statement a much stronger document than might be first viewed. That said, the Professional Statement was an opportunity to set out concrete standards to help regulate for higher standards as well as clearer templates to assist their membership to do this. Instead, there remains a reluctance to be seen to be too onerous or requiring a revolutionary shift in practice.

Given the evidence presented here on standards for eight years, for so many active professionals to either upgrade their practice or explain a viable rationale for not doing, seems unlikely. This, then, places the RICS into a situation where, potentially, so many of its members are failing to follow a Professional Statement. Watch this space!

\section{References}

Calvert, J. (2008) The Loughborough Report 2008. Loughborough University Enterprises: Loughborough.

Drivers Jonas (1990) Whose Money is it Anyway?. London: Drivers Jonas.

Drivers Jonas (1995) Whose Money is it Anyway?. London: Drivers Jonas.

Drivers Jonas (2000) Whose Money is it Anyway?. London: Drivers Jonas.

Eccles, T., and Holt, A. (2009) Service charges within the UK office market: evidence on accounting practice, compliance and disclosure. Brentford, U.K : Antim Research.

Eccles, T., Holt, A., Zatolokina, A. (2011) Commercial service charge management: benchmarking best practice", Journal of Corporate Real Estate, Vol. 13 Issue: 4, pp.200-215.

Edward, C. and Krendel, P. (2007) Institutional Leases In the 21st Century. London: EG Books.

Guide to Good Practice Working Party (2000) Service Charges in Commercial Property: A Guide to Good Practice, 2nd ed. 
Halvitigala, D. (2018) The effect of service charge responsibilities on tenants' leasing experience and satisfaction: A New Zealand perspective. Journal of Corporate Real Estate 20 (1): 41-55.

Holt, A. and Eccles, T. (2019) Leases as inhibitors of best practice in service charge management. Property Management. 37 (2): 275-286.

Holt, A. (2015) Commercial service charge accounting and audit: a review. Facilities. 33 (7/8), pp502-527.

Holt, A., Eccles, T. and Bennett, K. (2011) Accounting for service charges in the UK commercial sector: Barriers to change and the quest for best practice. Property Management 29(1), pp7-33.

Noor, M. N. M., and Pitt, M. (2009) A discussion of UK commercial property service charges. Journal of Retail \& Leisure Property 8(2): 119-138.

Jones Lang LaSalle (2012) Office Oscar 2012 - Service Charge Analysis for Offices. Available:http://www.joneslanglasalle.co.uk/MediaResources/EU/Marketing/UnitedKi ngdom/OSCAR-2012-Office.pdf (Accessed 8 October 2013).

RealService (2013) RealService Benchmarks [Online]. London: RealService, Available: http://www.real-service.co.uk/services-benchmarks.html (Accessed 8 October 2013).

RICS (2018) Service Charges in Commercial Property, $1^{\text {st }}$ edition. London:RICS.

RICS (2017) Consultation on 4th edition of the RICS Code of Practice for service charges in commercial property. London: RICS.

RICS (2014) Service Charges in Commercial Property, 3rd ed., London: Royal Institution of Chartered Surveyors.

RICS (2011) Service Charges in Commercial Property, 2nd Edition, London: RICS.

RICS (2010) Transparency in Professional Fees, RICS, London.

RICS (2009), "RICS launches transparency working group", available at:

www.rics.org/Newsroom/Pressreleases/pr04_rics_twg.htm (accessed 2 February 2009).

RICS (2006) Service Charges in Commercial Property, London: RICS.

Stapleton, T. (1985), Briefings for Surveyors 5 - Service Charges, Henry Stewart Publications, London

Unknown (1996) Service Charges in Commercial Properties - A Guide to Good Practice. 